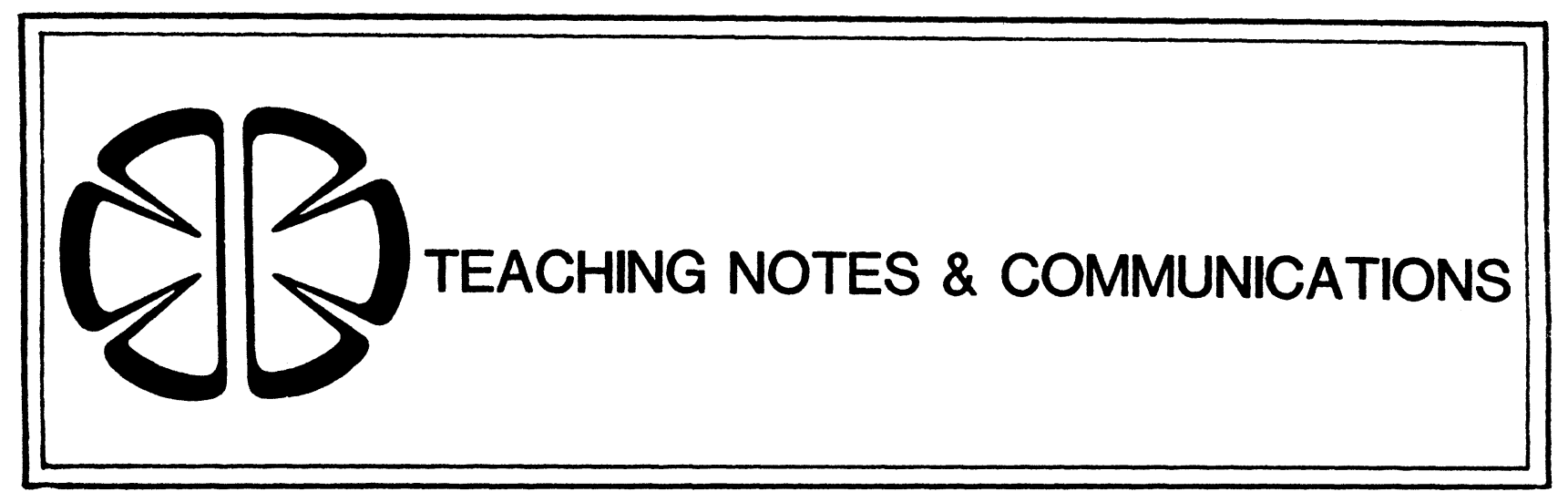

\title{
Reinforce Marketing Concepts with an Industry Marketing Film
}

\author{
George Nastas III
}

This article reports the use of the film, "Is Anybody Listening?" by the Procter and Gamble Company, in an undergraduate introductory marketing course. The film is very useful for both summarizing and concluding the course and in highlighting and reinforcing, in terms of industry application, some of the more important marketing concepts which the student should take from the course.

\section{RESOURCE TYPE: $16 \mathrm{~mm}$ Color Film}

Resource Emphasis Area: Marketing (Overview)

Description: This is a 28 -minute, color, $16 \mathrm{~mm}$ film titled, "Is Anybody Listening?" The film provides an overview of marketing as it is practiced at the Procter and Gamble Company. Particular emphasis is put on how the company listens and responds to customer wants and needs in the marketing of such familiar P\&G products as Crest, Pringles, Crisco, and Tide. Interviews are presented with company employees working in the areas of product development, consumer affairs, market research, and sales. There is no teacher's guide accompanying the film.

George Nastas III is Assistant Professor of Marketing, School of Management, University of Michigan-Flint, Flint, Michigan.
Comments: The film presents a very good look at a major consumer goods company's marketing operations. The film is best used in an introductory marketing course. It provides a good overview of marketing, but it does not supply an in-depth look at any elements of marketing. The film can easily be worked into a course schedule and it is compatible with the objectives of an introductory marketing course. Students will find the film interesting, informative, and entertaining.

Availability: This film is available on free loan from Modern Taking Pictures Service, 5000 Park Street North, St. Petersburg, Florida 33709. Specify the film "Is Anybody Listening?" by Procter and Gamble (film number 31431) and the desired showing date. This company also has many other films available for free loan, so ask for a free information bulletin. 
Teaching Notes: I have used this film for three years in my Introduction to Marketing course for junior level business undergraduates. This versatile film may be used in a variety of ways, such as to: (1) introduce the field of marketing and to spark student interest; (2) emphasize customer input into marketing decision making; (3) integrate the elements of marketing into a unified whole;
(4) demonstrate elements of product marketing for some well known brands; and (5) demonstrate various jobs available within the field of marketing. I have successfully used the film at the conclusion of the course to summarize and reinforce important marketing concepts which the student should take from the course.

\title{
A New Exam Policy for Large Lecture Courses: The Win-Win Solution
}

\author{
Terry Paul
}

Simple innovations which prove both popular with students and work-reducing for instructors, while maintaining academic integrity, are rare pearls that may be as close to the elusive free lunch as we can get. Probably more by accident than design, I have developed such an exam policy which is especially helpful to teachers of those increasingly common classes of 100-plus we face in marketing, although its usefulness is not limited only to our particular subject or large classes. This innovative exam policy combines two integral elements, viz. (1) three objective-question, no make-up midterm tests, along with (2) an optional, comprehensive essay question final exam. Each part, described briefly below as I implement it, can be modified somewhat in practice to suit the instructor, course, and students involved. What is essential, however, is the unaltered combination of no make-up opportunities for midterms along with the option of taking the final examination in the course.

Terry Paul is a Professor of Marketing at lowa State University, Ames, lowa.
The midterms. It's best to announce (and, of course, stick to) the dates of the midterms as early as possible and to clearly explain that absolutely no excuse is sufficient cause for receiving the opportunity to make up a midterm not taken. While admittedly arbitrary, this policy eliminates all the hassles of considering requests for make-ups, arranging for some or all students to take make-ups, preparing and grading separate exams, etc. I would argue that the policy is actually no more arbitrary than one of allowing some (more legitimate? more documentable?) requests and not others to take make-ups or attempting to reconcile the comparability of different exams taken at different times. What is beyond doubt in my experience is the simple ease of this policy and its enthusiastic acceptance by students. Fully 95\% of all students now typically take all three midterms offered despite previous prevalence of grandparent mortality, inoperative automobiles, and sudden illnesses on the exam eves. The option of avoiding the final exam makes it all worthwhile.

The final. I feel most comfortable making the final exam an essay type (where the 